\title{
Broadband Waveform Observation of the 28 June 1991 Sierra Madre Earthquake Sequence $\left(M_{L}=5.8\right)$
}

\author{
by Kuo-Fong $\mathrm{Ma}^{1}$ and Hiroo Kanamori
}

\begin{abstract}
The Sierra Madre earthquake $\left(M_{I}=5.8\right)$ of 28 June 1991 occurred at a depth of about $12 \mathrm{~km}$, on the Clamshell-Sawpit fault in the San Gabriel Mountains. High-quality seismograms were recorded with TERRAscope not only for the mainshock but also for the aftershocks at epicentral distances of about $16 \mathrm{~km}$. We determined the focal mechanisms and seismic moments of the mainshock and 21 aftershocks by combining the waveform and first-motion data. We classified the events into five groups according to the location and waveforms recorded at PAS. Most events located within $5 \mathrm{~km}$ west of the mainshock are similar to the mainshock in waveform. The mechanisms thus determined are thrust mechanisms. A few events located east of the mainshock have waveforms different from the mainshock and have strike-slip mechanisms. The average $Q_{\beta}$ values along the paths from the hypocenters of the Sierra Madre and the 3 December 1988 Pasadena earthquake $\left(M_{L}=4.9\right)$ to PAS are about 130 and 80 , respectively. The stress drop of the mainshock is about 500 bars. Most of the aftershocks have stress drops between 10 and 100 bars.
\end{abstract}

\section{Introduction}

The recent deployment of TERRAscope, a broadband and wide dynamic range seismic network in southern California, provided us with a capability of recording complete waveforms of nearby earthquakes. These waveform data allow us to determine the focal mechanisms, seismic moments, stress drops, and attenuation characteristics of the crust. The mechanisms of regional earthquakes are traditionally determined from $P$-wave firstmotion data, which are usually very sparse for small events and only represent the very beginning of fault motion, but do not necessarily represent the overall fault motion. A combined use of broadband waveforms and first-motion data enables us to obtain the overall mechanism that explains the first-motion and waveform data. This method can be used for single-station source-parameter determinations, because of recent availability of broadband stations. It is especially useful for small events, for which first-motion data are sparse and less reliable, but the waveform data are well recorded by nearby broadband instruments.

The 28 June 1991 Sierra Madre earthquake $\left(M_{L}=\right.$ $5.8)$ sequence occurred at a depth of about $12 \mathrm{~km}$, only about $16 \mathrm{~km}$ away from the Pasadena TERRAscope station (PAS), providing us with a good opportunity to use

\footnotetext{
${ }^{1}$ Present address: Institute of Geophysics, National Central University, Chung-Li, Taiwan 320-54, Republic of China.
}

broadband data for determining the overall characteristics of this sequence.

The PAS station recorded on-scale waveforms of the mainshock and the aftershocks. The focal mechanism of the mainshock determined from regional and local body waveforms is a thrust mechanism (Dreger and Helmberger, 1991). The average slip is approximately $50 \mathrm{~cm}$ in a small rupture area of about $12 \mathrm{~km}^{2}$ (Wald, 1991). The aftershock distribution and the focal mechanism of the mainshock suggest that the Sierra Madre earthquake was on the Clamshell-Sawpit fault in the south central part of the San Gabriel Mountains (Hauksson, 1994).

The seismicity in the Los Angeles basin and the adjacent areas has been high for the last $4 \mathrm{yr}$ (Hauksson and Jones, 1991). From 1900 through 1986, no earthquake larger than magnitude 4.9 occurred in the San Gabriel Valley, while four earthquakes (the 1987 Whittier Narrows $M_{L}=5.9$; the 1988 Pasadena $M_{L}=4.9$; the 1990 Upland $M_{L}=5.2$; and the 1991 Sierra Madre $M_{L}$ $=5.8$ ) with magnitude of 4.9 or larger have occurred since 1987.

We determined the focal mechanisms, seismic moments, and stress drops of the mainshock and the aftershocks of the Sierra Madre earthquake sequence using the waveforms recorded with broadband instruments. Since these events are very close to the PAS station, the waveforms at the PAS station allowed us to perform reliable source-mechanism determinations. We inverted the 
waveform data of the mainshock and 21 aftershocks with magnitudes equal to or larger than 1.5 recorded at PAS in conjunction with the first-motion data from the Southem California Seismic Network (SCSN). Just a few hours after the mainshock, Caltech installed a portable instrument at Mount Wilson (MWC), which is only $5 \mathrm{~km}$ away from the epicenter (Fig. 1). This instrument provided good waveform data for some of the aftershocks. For these events, we inverted the waveforms recorded at PAS and MWC simultaneously.

Because of the limitation of dynamic range and frequency band of traditional instruments, only a small range of earthquake magnitudes for a given source to receiver distance was recorded, resulting in incomplete data sets. The modern wide dynamic range broadband instrument can record on-scale waveforms for events with magnitudes ranging from 1.5 to 7 . The pulse width of $S H$ waves observed at short distances from the complete data set provides information on the stress drops of the events, and the attenuation characteristics of the crust along the path from the hypocenter to the PAS station. We used the well-recorded on-scale waveform to determine overall source mechanisms and measured the observed pulse width of $S H$ waves to estimate the stress drop of the events, which reflects the state of the stress in the fault zone, and the attenuation factor, $Q$, which reflects the degree of fracturing in the fault zone and shallow crust, to understand the overall characteristics of the earthquake sequence.

\section{Data}

One hundred and nine aftershocks were recorded by the Caltech-USGS Southern California Seismic Network during the period from 28 June 1991 to 31 August 1991 in the area shown in Figure 1. Of these, 22 events with a magnitude 1.5 or larger were recorded with the Pasadena (PAS) very broadband TERRAscope station (Table 1). We rotated the broadband records into the transverse and radial components, and deconvolved the instrument response from them to obtain ground-motion displacement records. We high-pass filtered the records of the aftershocks at $0.33 \mathrm{~Hz}$ to remove the large microseismic noise with periods of 4 to $8 \mathrm{sec}$.

The portable instrument deployed by Caltech at the Mount Wilson (MWC) station had a broadband Ranger seismometer with a flat velocity response from 0.05 to $20 \mathrm{~Hz}$. Twenty-six aftershocks were recorded with the portable instrument at MWC. This instrument provided good waveform data for six of the aftershocks (Table 1). We rotated the records, and integrated them to obtain the displacement records. The records were high-pass filtered at a corner frequency of $0.5 \mathrm{~Hz}$.

We classified the events into five groups according
Seismicity 28 June -- 31 August 1991

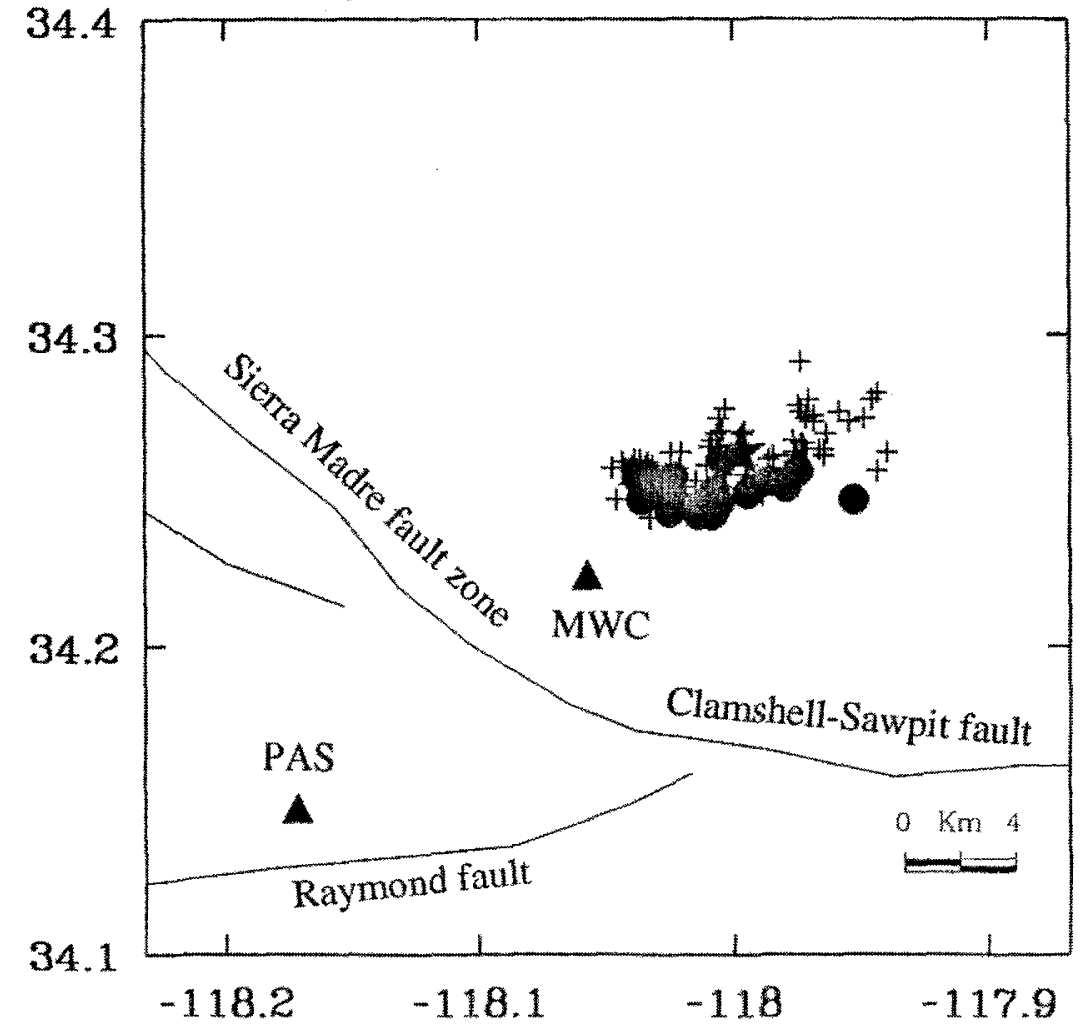

Figure 1. Seismicity during the time period from 28 June to 31 August in the study area. Cross symbols and solid circles represent the aftershocks recorded by the Caltech-USGS Southern California Seismic Network and events with magnitude 1.5 or larger recorded by PAS TERRA TERRAscope station, respectively. The asterisk indicates the mainshock. 
to the epicenters and the waveforms recorded at PAS station. The events in group I (Fig. 2a) are very similar to the mainshock in waveform. They show a small upward $P$ wave, and an $S$ wave with a large negative (clockwise around the epicenter) transverse component and a negative (toward the epicenter) radial component. There are nine events in group I, including the mainshock. This similarity suggests that the mechanisms of the events are similar to that of the mainshock. The waveform of event 3 in group I is particularly similar to that of the mainshock. This is one of the largest aftershocks, with a magnitude of 4.0. Other events in group I have magnitudes of 1.6 to 3.3. They show a downward double-peaked $S$ wave on the tangential component. Event 6 has a nodal $S H$ wave.

There are five events in group II (Fig. 2b), which are essentially similar to those of group I, except that the $P$ wave shows a small downward motion. The small $P$ waves in groups I and II suggest that the PAS station is close to the node of the $P$-wave radiation pattern. Group III (Fig. 2c) has three events with distinct upward $P$ wave motion, and an $S$ wave with a positive transverse component and a negative radial component. Event 1 in this group has a magnitude of only 1.5 and the record is very noisy. Group IV (Fig. 2d) has two small events with magnitudes of 1.6 and 1.5. They also show noisy waveforms and the polarities of $P$ - and $S$-wave motions are similar to those of group I. However, the amplitude of the $P$ wave on the vertical component is about the same as that of the $S$ wave. Group V (Fig. 2e) has three events. The waveforms of events 1 and 2 have different polarities of $P, S V$, and $S H$ from those of any other aftershocks. The waveforms of the third event in group V are similar to those in group II. However, the location of this event is farther east from the cluster of group II (Fig. 5).

The rotated displacement records for the six events recorded at MWC are shown in Figure 3. They show distinct $P$ - and $S$-wave motions. Three events in group I were recorded by the portable instrument. Since the MWC station is close to the nodes of the events, despite the similarity in waveforms of the events at PAS station, the waveforms of the three events at MWC are different.

\section{Method}

The method used in this study is essentially the same as that used by Ma and Kanamori (1991). The $P, S V$, and $S H$ far-field displacements, $U_{r}, U_{\theta}$, and $U_{\phi}$, from a double-couple point source, are given by

Table 1

The Origin Time, Location, Fault Parameters, and Seismic Moment of the Mainshock and Twenty-One Aftershocks of the Sierra Madre Earthquake in Five Groups. Stations Used are Indicated by a Cross under the Station Name.

\begin{tabular}{|c|c|c|c|c|c|c|c|c|c|c|c|}
\hline Event & $\begin{array}{l}\text { Time } \\
\text { (GMT) }\end{array}$ & $\begin{array}{l}\text { Latitude } \\
(\mathrm{N})\end{array}$ & $\begin{array}{l}\text { Longitude } \\
\text { (W) }\end{array}$ & $\begin{array}{l}\text { Depth } \\
(\mathrm{km})\end{array}$ & M & PAS & MWC & $\begin{array}{l}\text { Dip } \\
\left({ }^{\circ}\right)\end{array}$ & $\begin{array}{c}\text { Rake } \\
\left({ }^{\circ}\right)\end{array}$ & $\begin{array}{l}\text { Strike } \\
\left({ }^{\circ}\right)\end{array}$ & $\begin{array}{c}\text { Moment } \\
\text { (dyne-cm) }\end{array}$ \\
\hline \multicolumn{12}{|c|}{ Group 1} \\
\hline 0 & 6281443 & 34.263 & -117.998 & 12.54 & 5.8 & $\mathrm{X}$ & & 56.7 & 70.1 & -127.6 & $2.70 \mathrm{E}+24$ \\
\hline 1 & 6281620 & 34.254 & -118.034 & 12.09 & 1.6 & $\mathrm{X}$ & & 59.6 & 119 & 111.1 & $1.27 \mathrm{E}+19$ \\
\hline 2 & 6281658 & 34.253 & -117.987 & 11.13 & 3.3 & $\mathrm{x}$ & & 61.2 & 53.3 & -137.9 & $9.70 \mathrm{E}+20$ \\
\hline 3 & 6281700 & 34.250 & -117.994 & 11.12 & 4 & $\mathrm{X}$ & & 66.6 & 138.6 & 119.7 & $3.64 \mathrm{E}+22$ \\
\hline 4 & 6281755 & 34.255 & -118.038 & 13.31 & 2.1 & $\mathrm{X}$ & & 79.4 & 131.2 & 139.6 & $7.58 \mathrm{E}+19$ \\
\hline 5 & 6281950 & 34.247 & -118.036 & 12.00 & 1.8 & $\mathrm{X}$ & & 48.8 & 61.4 & 114.9 & $1.31 \mathrm{E}+19$ \\
\hline 6 & 6302140 & 34.247 & -118.025 & 11.40 & 2.2 & $\mathrm{X}$ & $\mathrm{X}$ & 35.561 & 109.58 & 85.63 & $4.73 \mathrm{E}+19$ \\
\hline 7 & 7051536 & 34.254 & -118.024 & 13.71 & 1.8 & $\mathrm{X}$ & $\mathrm{X}$ & 48.67 & 108.46 & -95.66 & $2.40 \mathrm{E}+19$ \\
\hline 8 & 7070745 & 34.254 & -118.038 & 13.26 & 1.7 & $\mathrm{X}$ & $\mathrm{X}$ & 51.94 & 39.09 & -130.75 & $8.46 \mathrm{E}+18$ \\
\hline \multicolumn{12}{|c|}{ Group 2} \\
\hline 1 & 6281459 & 34.254 & -118.035 & 13.22 & 3.2 & $\mathrm{X}$ & & 39.4 & 79.9 & 67.5 & $3.04 \mathrm{E}+21$ \\
\hline 2 & 6281513 & 34.250 & -118.008 & 10.35 & 2 & $\mathrm{X}$ & & 47 & 155.5 & 143.6 & $2.93 E+19$ \\
\hline 3 & 6281517 & 34.260 & -118.005 & 11.58 & 2.1 & $\mathrm{X}$ & & 55.7 & 106.1 & -94.5 & $1.64 \mathrm{E}+19$ \\
\hline 4 & 6281852 & 34.247 & -118.010 & 11.08 & 3.1 & $\mathrm{X}$ & & 60.1 & 145 & 131.6 & $7.87 \mathrm{E}+20$ \\
\hline 5 & 6300214 & 34.243 & -118.025 & 10.94 & 2.3 & $\mathrm{X}$ & $\mathrm{X}$ & 58.5 & 106.93 & -102.9 & $9.50 \mathrm{E}+20$ \\
\hline \multicolumn{12}{|c|}{ Group 3} \\
\hline 1 & 6281553 & 34.243 & -118.008 & 9.55 & 1.5 & $\mathrm{X}$ & & 17.5 & 26.4 & -157.9 & $2.49 \mathrm{E}+18$ \\
\hline 2 & 6281711 & 34.242 & -118.014 & 11.19 & 2.2 & $\mathrm{X}$ & & 30.4 & 10.8 & -163.5 & $8.76 \mathrm{E}+19$ \\
\hline 3 & 7062254 & 34.242 & -118.009 & 10.92 & 4 & $\mathrm{X}$ & $\mathrm{X}$ & 88.18 & 105.85 & 97.19 & $6.67 \mathrm{E}+21$ \\
\hline \multicolumn{12}{|c|}{ Group 4} \\
\hline 1 & 6281716 & 34.249 & -117.995 & 9.59 & 1.6 & $\mathrm{X}$ & $\mathrm{X}$ & 59.13 & 44.96 & -146.31 & $3.52 \mathrm{E}+18$ \\
\hline 2 & 6291150 & 34.256 & -117.975 & 9.48 & 1.5 & $\mathrm{X}$ & $\mathrm{X}$ & 56.3 & 29.83 & -143.55 & $4.55 \mathrm{E}+18$ \\
\hline \multicolumn{12}{|c|}{ Group 5} \\
\hline 1 & 6281537 & 34.251 & -117.980 & 13.09 & 3.5 & $\mathrm{X}$ & & 67.6 & 170.7 & -74.1 & $7.21 \mathrm{E}+21$ \\
\hline 2 & 6281953 & 34.246 & -118.006 & 10.39 & 1.9 & $\mathrm{X}$ & & 75.7 & -32.1 & 126.6 & $2.00 \mathrm{E}+19$ \\
\hline 3 & 8142150 & 34.248 & -117.950 & 10.40 & 3 & $\mathrm{X}$ & & 89.5 & -171.5 & -17.9 & $7.03 \mathrm{E}+20$ \\
\hline
\end{tabular}




$$
\left[\begin{array}{c}
U_{r} \\
U_{\theta} \\
U_{\varphi}
\end{array}\right]=\frac{M_{0} s(t)}{4 \pi \rho r \alpha^{3}}\left[\begin{array}{c}
R^{P} \\
(\alpha / \beta)^{3} R^{S V} \\
(\alpha / \beta)^{3} R^{S H}
\end{array}\right],
$$

where $s(t)$ and $M_{0}$ are the unit moment rate function and the seismic moment, respectively. Here, $\rho, \alpha$, and $\beta$ are density, $P$ velocity, and $S$ velocity, and $R^{P}, R^{S V}$, and $R^{S H}$ are $P$-wave, $S V$-wave, and $S H$-wave radiation patterns, respectively. The radiation patterns are functions of the fault parameters: dip $\delta$, rake $\lambda$, and strike $\phi$. We use equation (1) to determine $M_{0}, \delta, \lambda$, and $\phi$ from $U_{r}, U_{\theta}$, and $U_{\phi}$, estimated from the observed $P, S V$, and $S H$ amplitudes and polarities.

Let $U_{P}, U_{S V Z}, U_{S V R}$, and $U_{S H}$ be the displacements of the $P$ wave on the vertical component, the $S V$ wave on the radial component, and the $S H$ wave on the tangential component, respectively, observed at the free surface, and then

$$
\begin{gathered}
U_{r}=U_{P} /\left(2 \cos i_{0}\right) \\
U_{\theta}=U_{S V Z} /\left(-2 \sin i_{0}\right)=U_{S V R}\left(2 \cos i_{0}\right) \\
U_{\phi}=U_{S H} / 2,
\end{gathered}
$$

Event 0

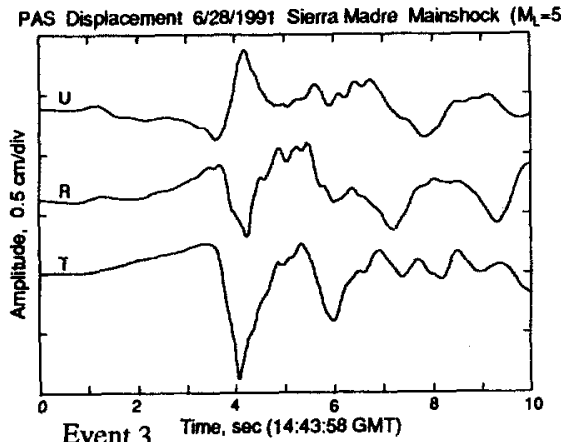

Event 3 Time, sec (14:43:58 GMT)
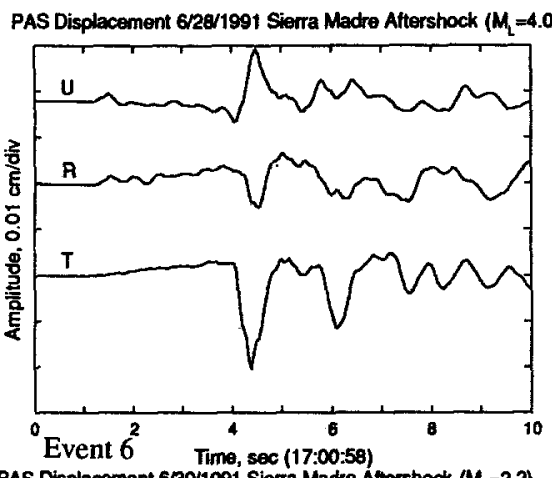

PAS Displacement 6/30/1991 Sierra Madre Almorshock $\left(M_{L}-2.2\right)$

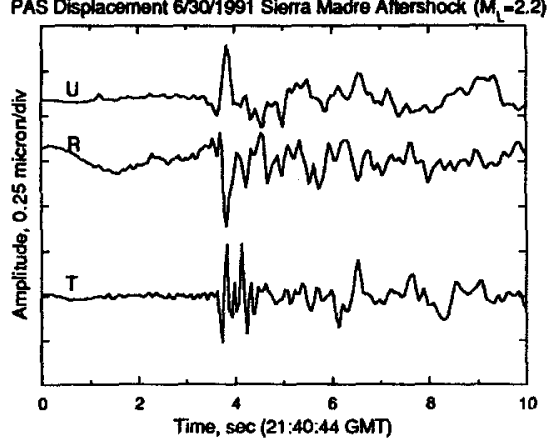

Event 1 Group I PAS Displacement 6/28/91 Sierra Madre Aftershock $\left(M_{L}=1.6\right)$

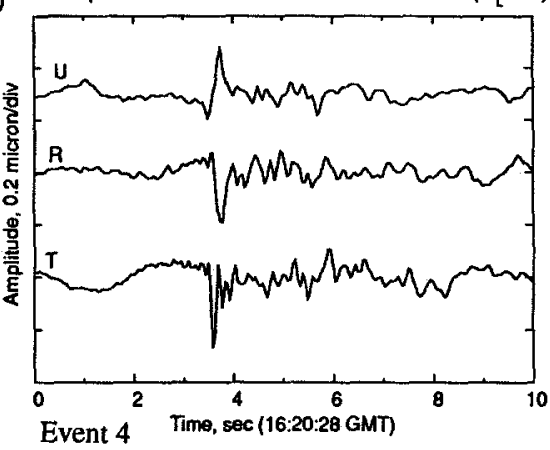

PAS Displacement 6/28/1991 Sierra Madre Aftershock $(M-2.1)$
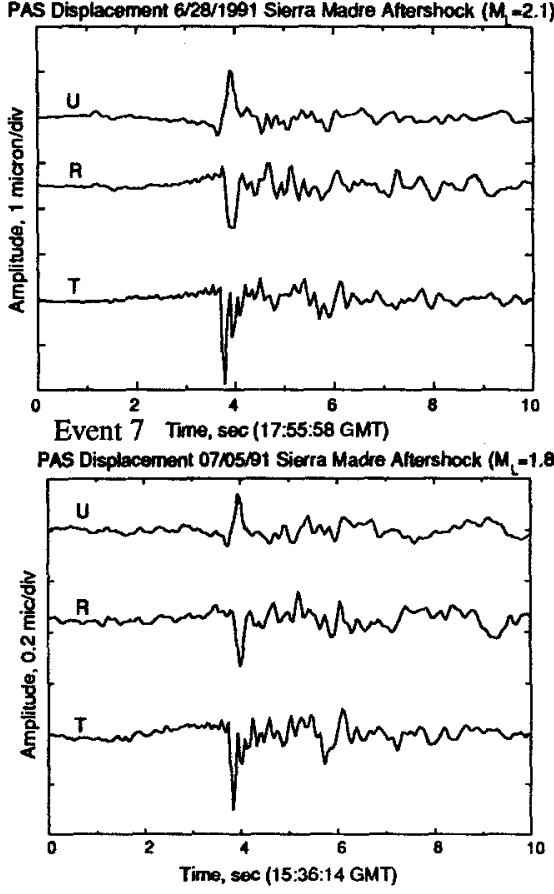

Event 2

PAS Displacement 6rz's/91 Sierra Madre Aitershock ( $M$. $=3.3$ )

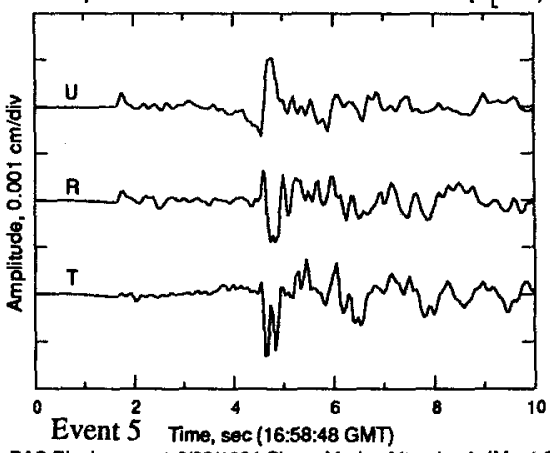

PAS Displacement 6/28/1991 Sierra Madre Aftershock ( $M=1.8$ )

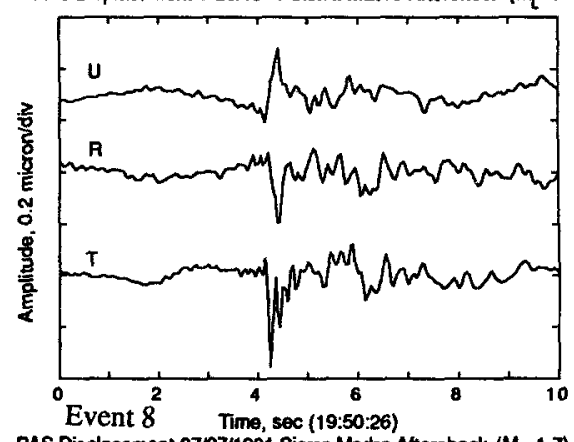

PAS Displacement 07107/1991 Sierra Madre Atiershock $\left(M_{2}=1.7\right)$

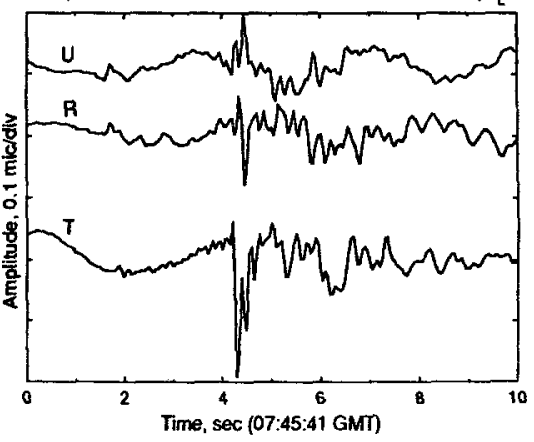

(a)

Figure 2. Rotated displacement records of the mainshock and 21 aftershocks in five groups. The amplitude scale indicates the true ground-motion amplitudes. Note that the scales vary; $U=$ vertical, $T=$ transverse, $R=$ radial. (a) The mainshock and eight aftershocks of group I, (b) five aftershocks of group II, (c) three aftershocks of group III, (d) two aftershocks of group IV, and (e) three aftershocks of group $\mathrm{V}$. 
Event 1

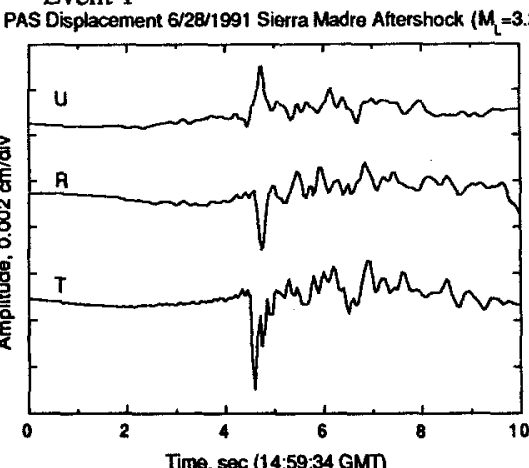

Event 4

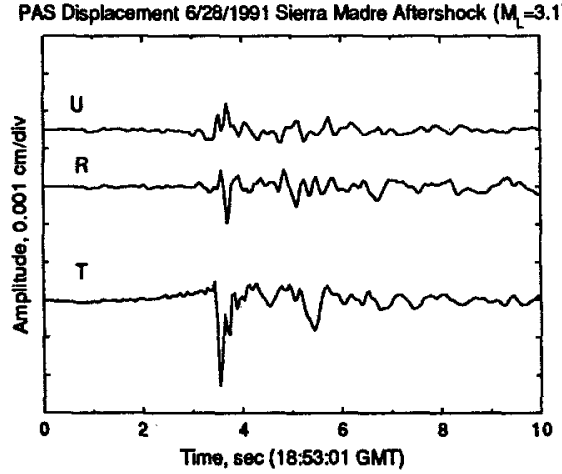

Event 1

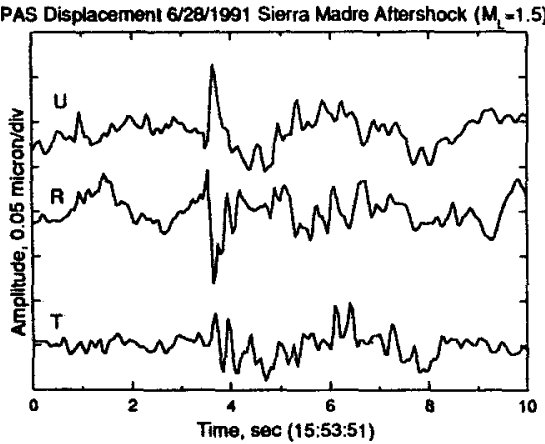

Event 2 Group II AS Displacement 6/28/91 Sierra Madre Aftershock $\left(M_{1}=2.0\right)$

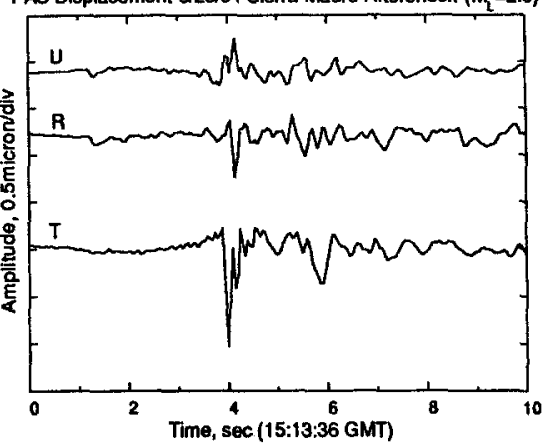

Event 5

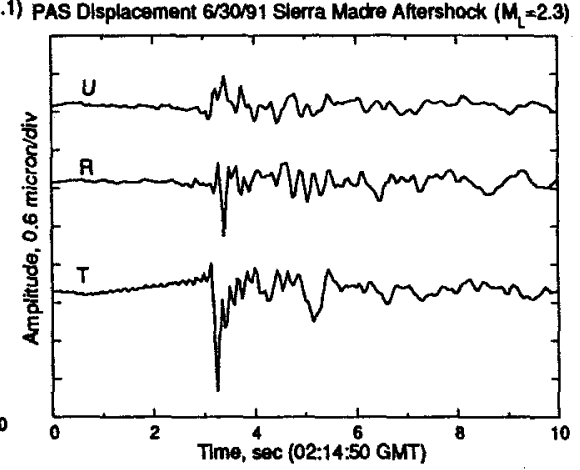

(b)

Event 3

PAS Displacement 06/28/91 Sierra Madre Aftershock $\left(M_{1}=2.1\right)$

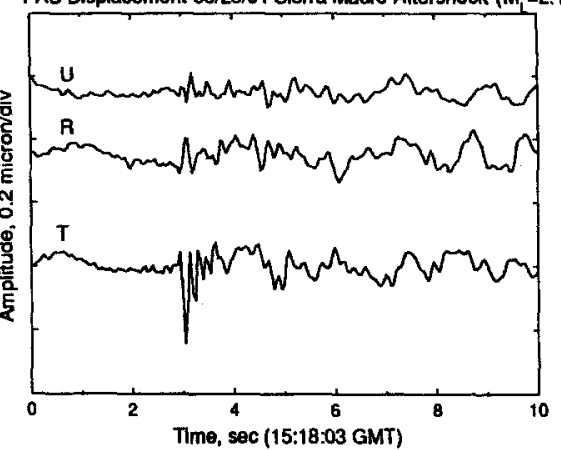

Time, sec (15:18:03 GMT)

AS Displacemonis/28/1991 Sierra Madre Athershock (M $=2$ 2)

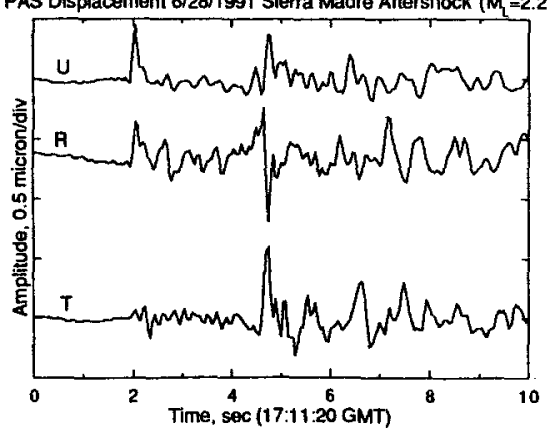

Event 3

PAS Displacement 7/06/1991 Sierra Madre Aftershock ( $M=4.0$ )

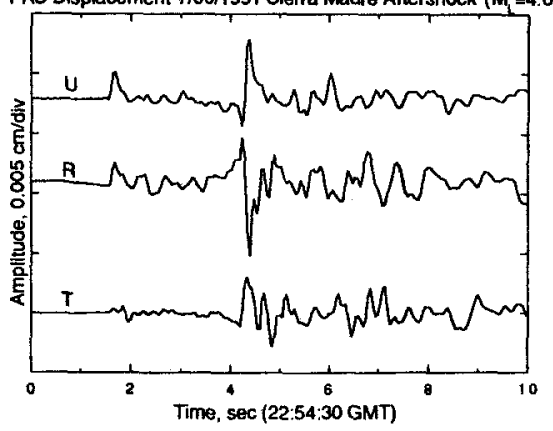

(c)

Group IV

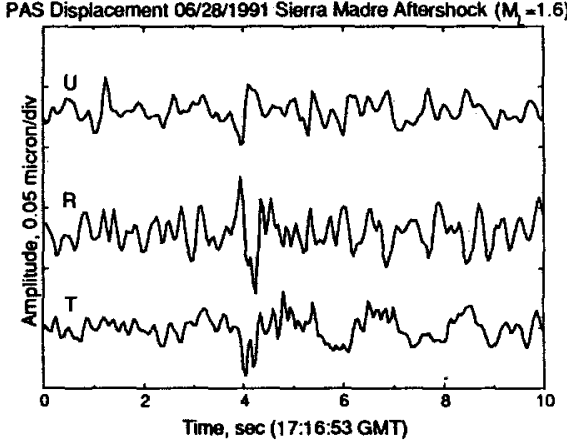

Event 2

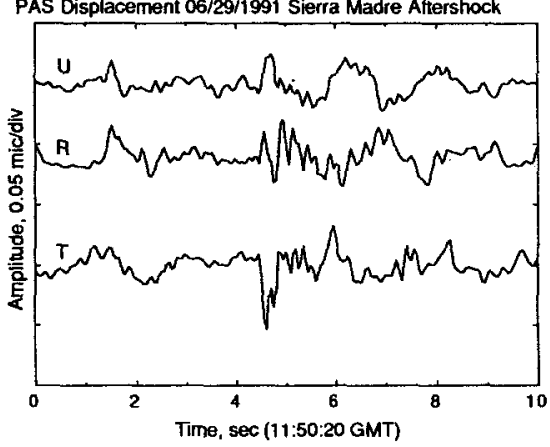

(d)

Figure 2-Continued 
Event 1

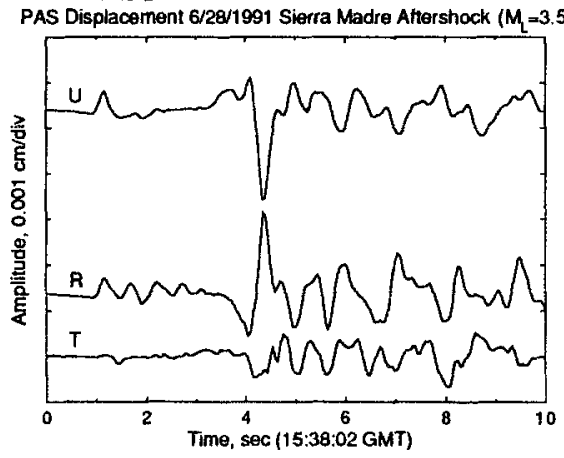

Event 2 Group V

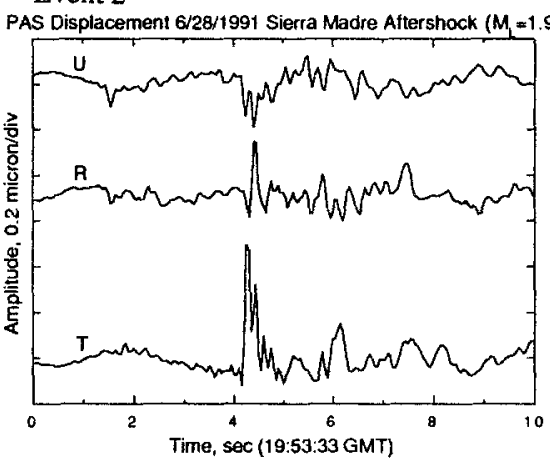

(e)
Event 3

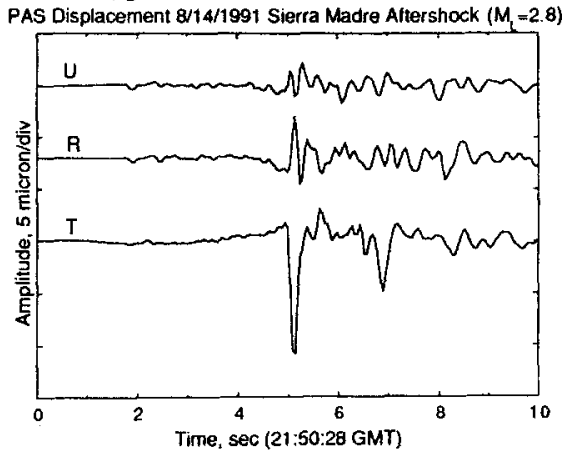

Figure 2-Continued
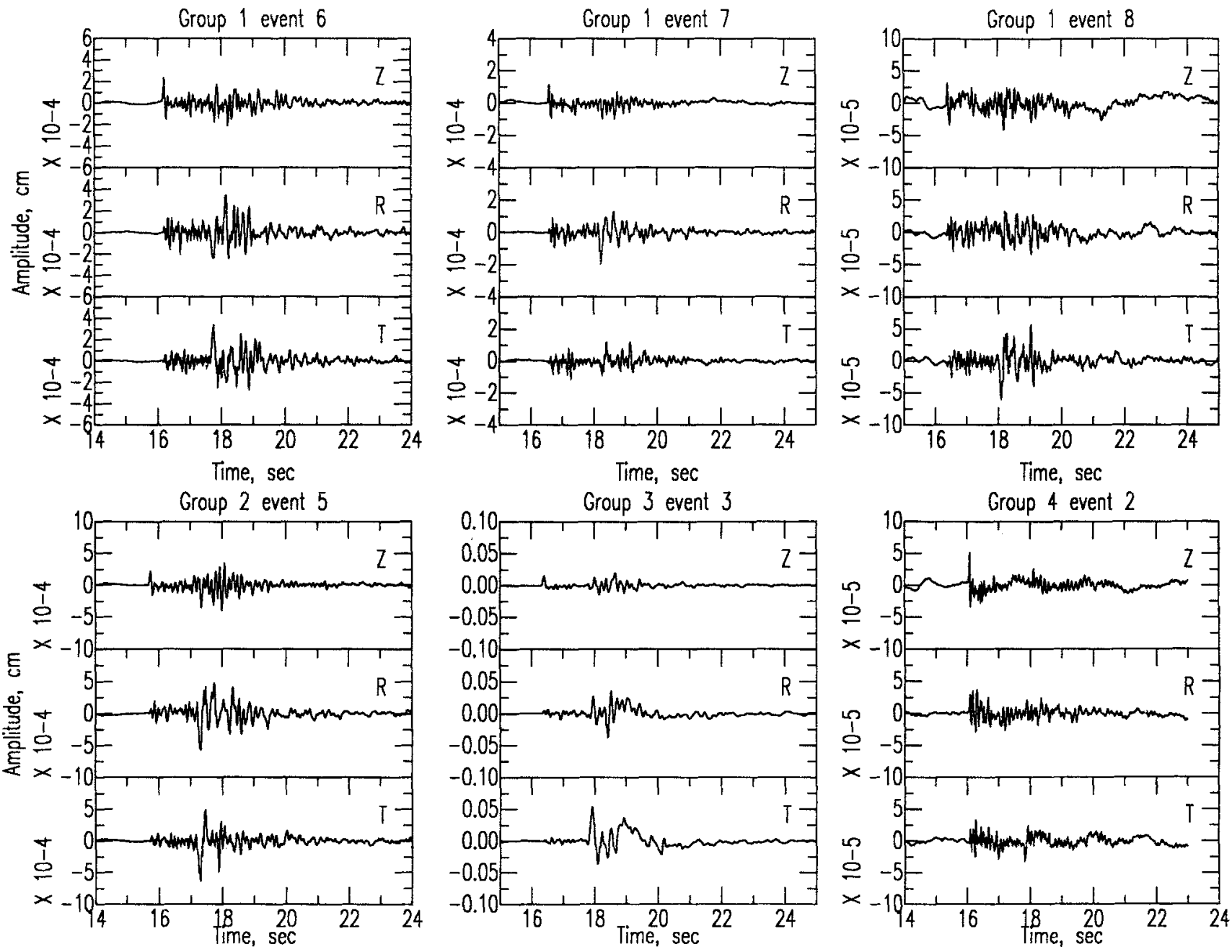

Figure 3. Rotated displacement records for the six events recorded by portable instruments at the MWC station. The amplitude scale indicates the true groundmotion amplitude. 
where $i_{0}$ is the incidence angle. The free-surface effect is approximated by a factor of 2 of amplification of the incidence wave. If $P-S V$ conversion at the surface is considered, $U_{r}$ and $U_{\theta}$ become more complex functions of the incidence angle. Since the effect of the free surface is generally smaller on the vertical component than on the radial component, we estimated $U_{\theta}$ from the vertical component. Within critical angle, the factor of 2 of the free-surface approximation is satisfactory.

In this study, we only use stations that are close to the epicenter. The propagation effect is simple and the free-surface approximation mentioned above is satisfactory. If only one station is available, the number of parameters, four, is larger than the number of data, three, in equation (1), and the solution of equation (1) is nonunique; thus, we obtained the solution by combining the waveform and first motion data. If waveform data from more than one station were available, the solution of equation (1) could be obtained without using the firstmotion data.

We determined the loci of the $P$ and $T$ axes, here called the inversion $P$-T loci (Fig. 4), which are consistent with the observed amplitudes and polarities of $P$, $S V$, and $S H$ waves. We combined the inversion $P-T$ loci with the ranges of $P$ and $T$ axes, which were determined by the program FPFIT (Reasenberg and Oppenheimer, 1985). The program FPFIT determines the first-motion mechanism and ranges of $P$ and $T$ axes that fit the firstmotion data recorded by SCSN. These ranges are called the first-motion $P$ - $T$ ranges (Fig, 4 ). If the inversion $P$ $T$ loci pass through the first-motion $P-T$ ranges, any solution for which the $P$ and $T$ axes lie in the overlapping region can satisfy both the first-motion and waveform data. If the inversion $P-T$ loci did not pass through the first-motion $P-T$ ranges, we chose a point on the inversion $P-T$ loci that is closest to the first-motion $P-T$ ranges. Since the magnitude of some of the aftershocks are in the range of 1.5 to 3 , the number of first-motion data available is small. For some small events, compressional and dilatation first motions are mixed, and so the firstmotion $P-T$ ranges of these events are not reliable. If we assumed that the events with similar waveforms and locations in the same group have similar mechanisms, we could use the first-motion $P-T$ ranges of the largest event in the group for the smaller events with poor first-motion data. For some small events, an alternative mechanism was determined using the first-motion data of the largest event in the same group. If there are two or more broadband stations available, we can solve equation (1) using the standard method of least squares.

\section{Results}

Focal Mechanism and Seismic-Moment

Determination

The mechanisms determined from the method described above for group I are shown in Figure $4 a$, to compare with the solutions determined from the firstmotion data alone. The mechanisms of events 6,7 , and 8 were determined from the waveform inversion of PAS and MWC stations. We also determined the mechanisms of event 6,7 , and 8 by combining the waveform and first-motion data. The solutions are similar to that from inversion of waveforms at two stations; the difference is only $5^{\circ}$ in strike.

The mechanisms of other events were determined by inverting the waveform at PAS and through the first-motion data. The $P$ and $T$ axes of these mechanisms are close to or within the overlapping regions of inversion $P-T$ loci and first-motion $P-T$ ranges. The magnitudes of events 4 and 5 are only about 2.1 and 1.8 ; the first-motion data are sparse and less reliable. Since, in general, similarities of waveforms and locations suggest similar mechanisms of the events, from the similar waveforms and location of the mainshock and events 4 and 5, we also determined the mechanisms of these two events using first-motion $P-T$ ranges of the mainshock to examine the reliability of the solutions we obtained for events 4 and 5. The solutions thus obtained using first-motion $P$ $T$ ranges of the mainshock are only different by less than $2^{\circ}$ in strike from those obtained using their own firstmotion $P-T$ ranges. It suggested that our solutions for events 4 and 5 are reliable even using their own sparse first motions.

Except for events 1, 4, and 5, the mechanisms of the events in group I thus determined are generally consistent with those from the first-motion data. These three events are very similar in waveforms (Fig. 2a) and locations (Fig. 5), but the first motions are very different, especially with the azimuths from $225^{\circ}$ to $315^{\circ}$. The first motions in this study had been rechecked by Hauksson (1992) to correct possible errors in determining their polarities and to include all important first motions. The hypocenters of the events had also been relocated by Hauksson (1992) using various velocity models to confirm the take-off angles for the events at each station. Therefore, the difference in first motions but similarity in waveform among events 1,4 , and 5 indicates that the fault motion in the beginning was different from the overall fault mechanism. The solution from the waveform data represents the overall mechanism. In general, the mechanisms of the events in group I thus obtained are similar to each other with a thrust fault mechanism.

The mechanisms obtained for group II are shown in Figure $4 \mathrm{~b}$, to compare with the solutions from the firstmotion data alone. Except for events 3 and 5, the inversion $P-T$ loci overlap with the corresponding firstmotion $P-T$ ranges. The solutions thus determined for these events can explain the waveform and first-motion data fairly well. The mechanisms for the three events are in general consistent with those from first motions. The $P$ and $T$ axes of the mechanism for event 3 were chosen from the point on the inversion $P-T$ loci that is close to 
the first-motion $P-T$ ranges. The resulting solution is very different from that from the first-motion data. Our solution has thrust fault mechanisms similar to those of the mainshock and other events in group II. This event has mostly compressive first motions for the stations with azimuths from $180^{\circ}$ to $270^{\circ}$, while the other events in group II have mostly dilatational first motions in the same regions. This discrepancy suggests that either the first motions of the magnitude 2.1 event are not reliable, or the beginning of fault motion is different from the over- all faulting mechanism, as we discussed for group I. The mechanism for event 5 was determined from the waveform inversion of PAS and MWC stations. The solution is similar to that from first-motion data. The overall mechanisms of the events in group II thus determined show thrust fault mechanisms similar to those of events in group I.

Figure $4 \mathrm{c}$ compares our solutions with that from the first-motion data for the events in group III. Since the event 1 of group III has a magnitude of only 1.5 , the

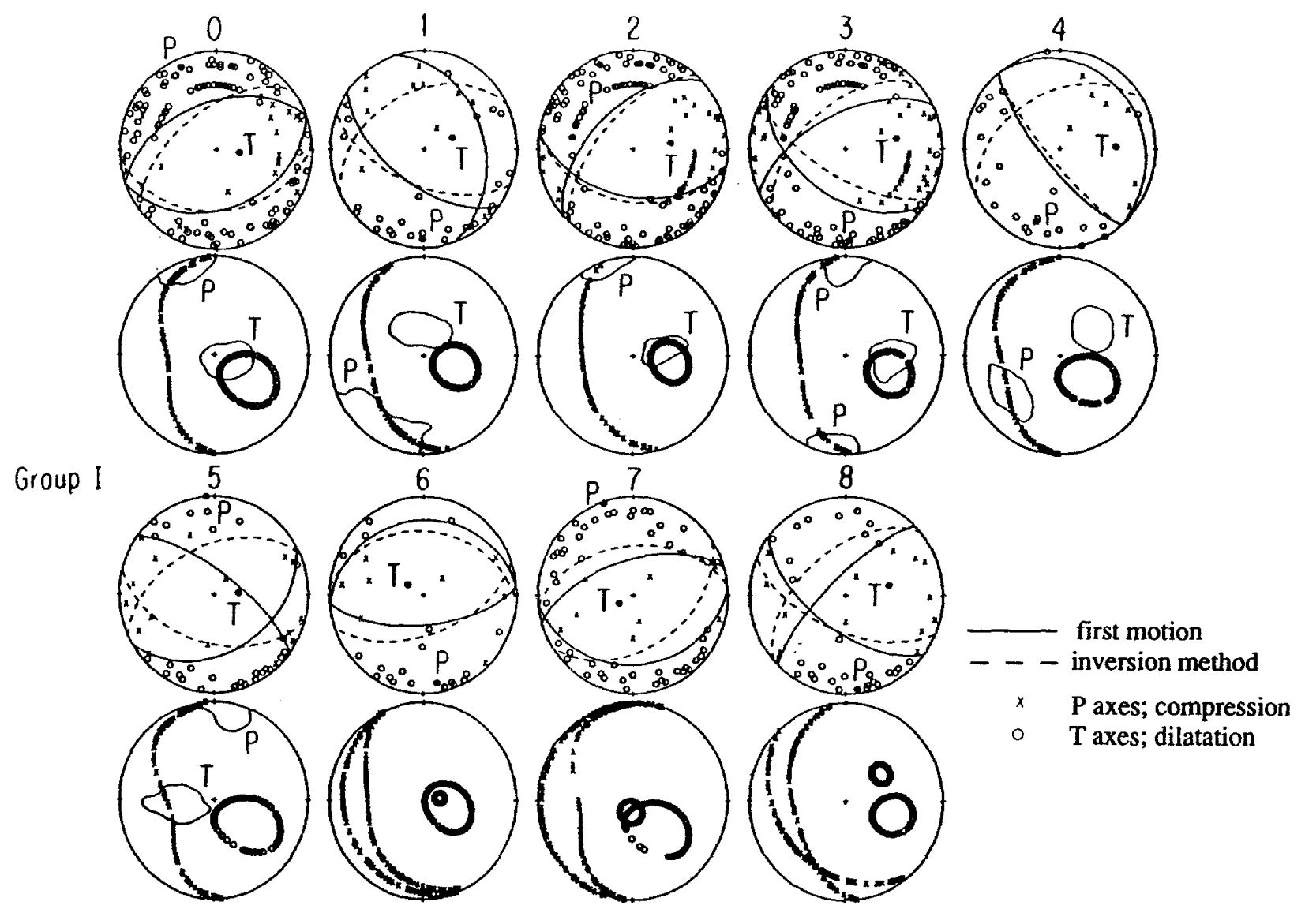

(a)

Figure 4. The first-motion data recorded by the Caltech-USGS Southern California Seismic Network and the focal mechanisms determined from the firstmotion data alone (solid curves), and the combined (first-motion and waveform) data (dashed curved) of the mainshock and 21 aftershocks of the 1991 Sierra Madre earthquake in five groups. The first-motion data and focal mechanism are shown by equal-area projection of the lower hemisphere. The dot symbols labeled with $P$ and $T$ indicate the $P$ and $T$ axes of our preferred solution. The figures beneath the first-motion data show the inversion $P-T$ loci and the first-motion $P$ $T$ ranges. The cross symbols and open circles indicate the compression and dilatation of first motions and $P$ and $T$ loci of inversion (a) The comparison of the mechanisms determined with our method and from first-motion data for the mainshock and eight aftershocks of group I, (b) group II, (c) group III, (d) group IV, and (e) group V. The mechanisms of events 6,7 , and 8 of group I, event 5 of group II, event 3 of group III, and events 1 and 2 of group IV were determined from the waveform inversion of PAS and MWC stations. The figures beneath the first-motion data for these events represent the inversion $P-T$ loci of PAS and MWC stations, respectively. 

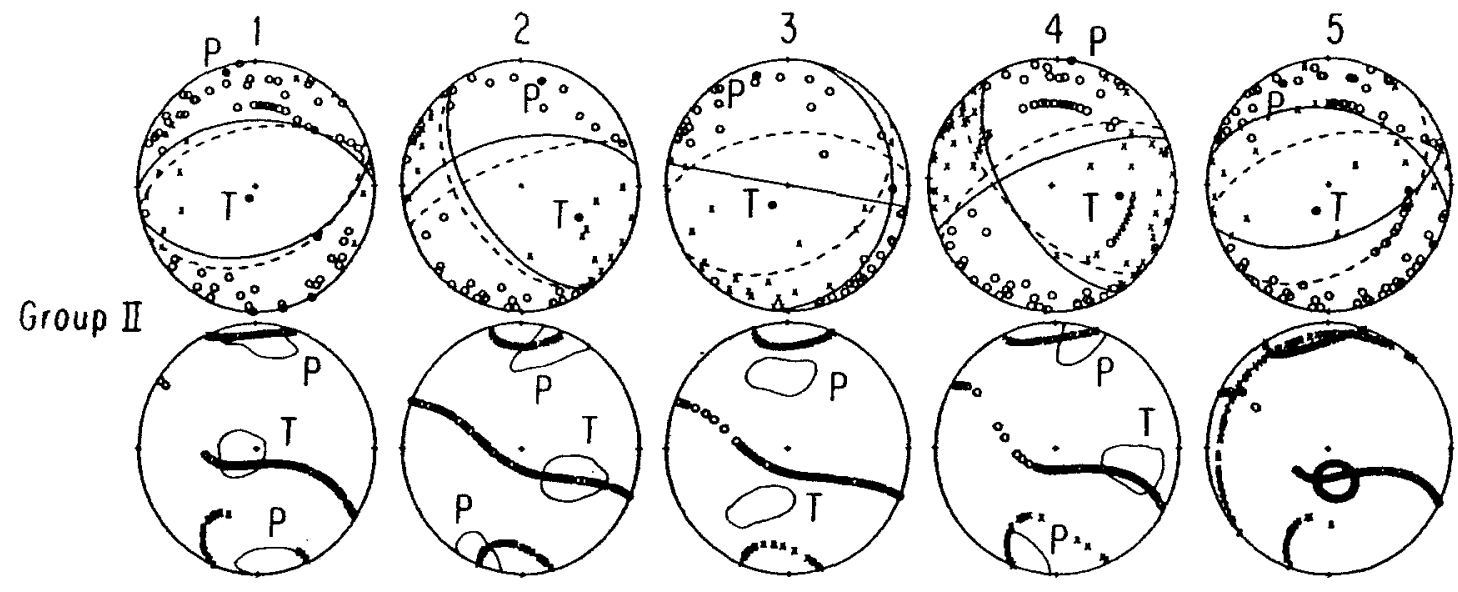

(b)
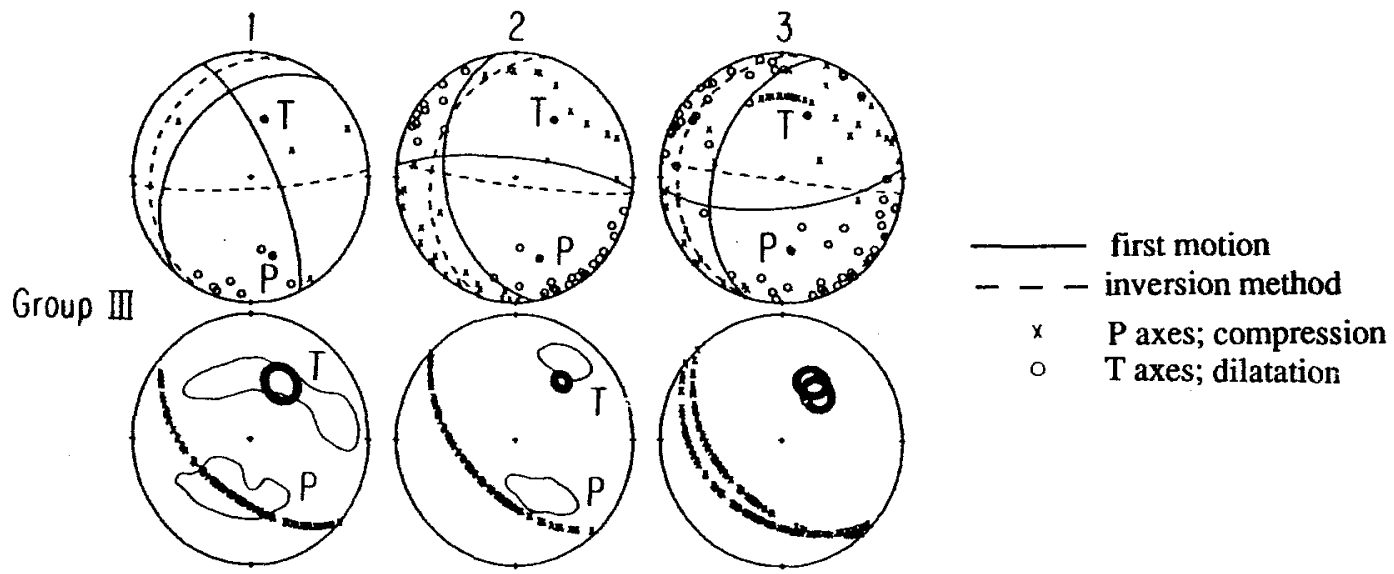

$\mathrm{T}$ axes; dilatation

(c)

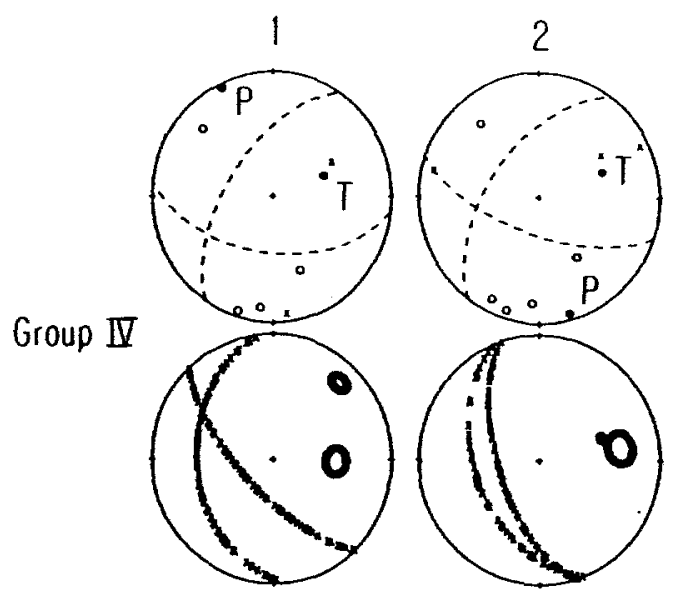

(d)

Figure 4-Continued

first motions are very sparse and the first-motion $P-T$ ranges are very large. The solution from waveform inversion and first-motion data of the events in group III show more strike-slip motion with a very steep fault plane.

The mechanisms for the two events in group IV shown in Figure 4d were determined by inverting the waveform at PAS and MWC stations. Since they are very small, the mechanisms from the first-motion data are not available. The waveform data at MWC station for event 1 are not available. Because of the similarity in waveforms and 


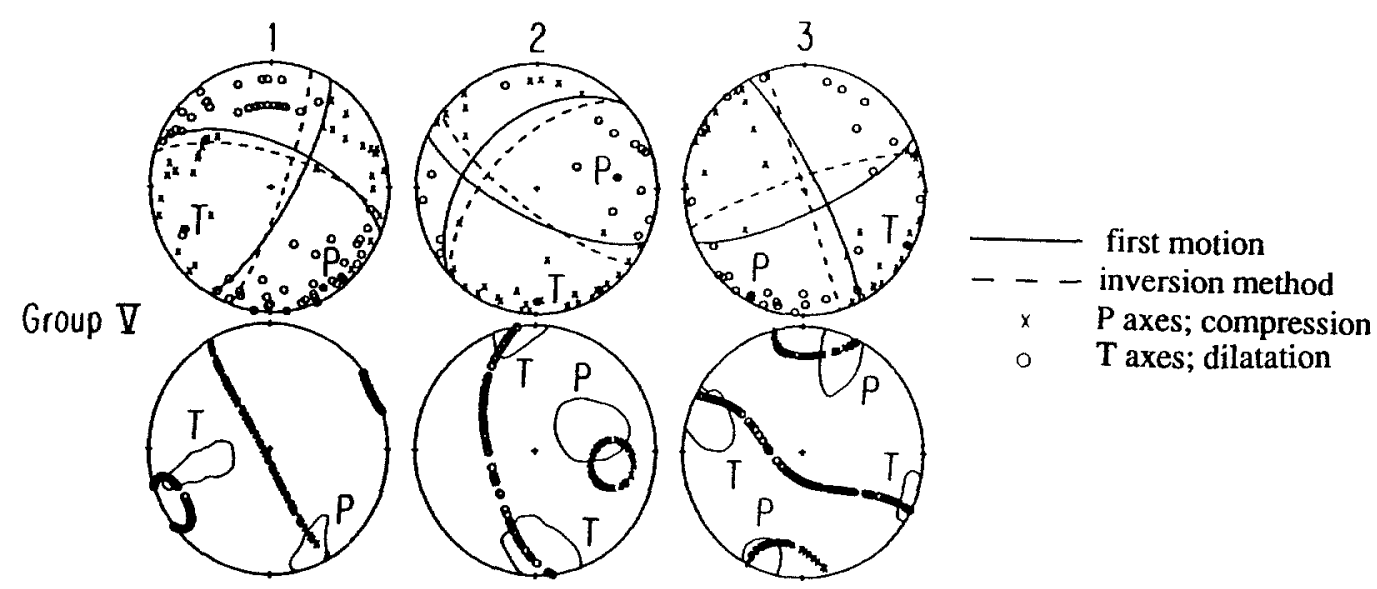

(e)

Figure 4-Continued

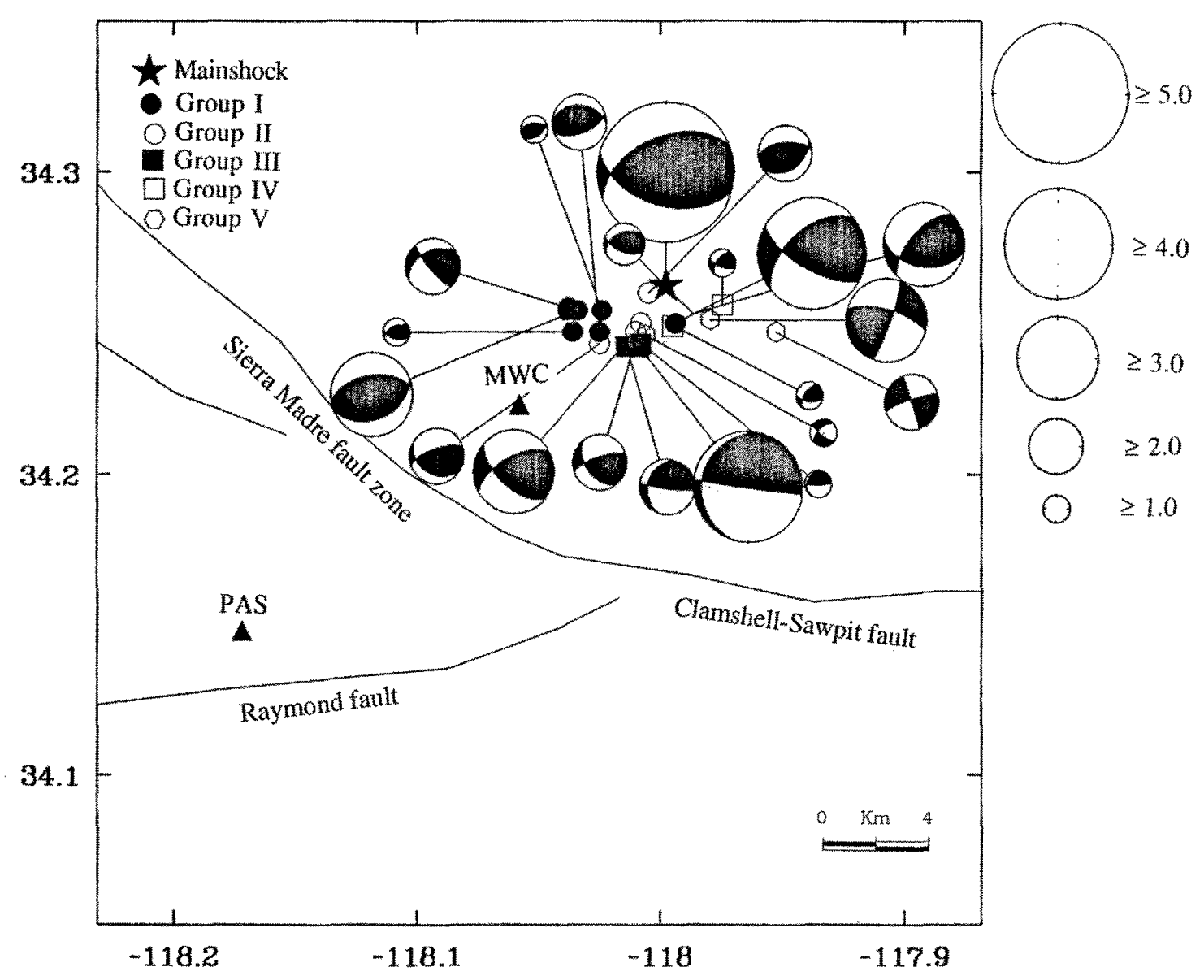

Figure 5. The spatial distribution of the mainshock and the aftershocks of the Sierra Madre earthquake sequence, with focal mechanisms shown by equal-area projections of the lower focal hemisphere, with the locations from the CaltechUSGS Southern California Seismic Network. The asterisks indicate the location of the mainshock. Solid circles, open circles, solid squares, open squares, and open hexagon symbols represent the locations of the events in five groups. The sizes of the mechanisms are proportional to the sizes of the events. 
locations of the two events, the data of event 2 at MWC station were used in event 1 , in combination with the data at PAS station, to determine the mechanism of event 1. The mechanisms thus obtained for the events in group $\mathrm{V}$ (Fig. 4e) are similar to those from the first-motion data. These events have strike-slip mechanisms that are very different from those of any other aftershocks.

Figure 5 shows the spatial distribution of the mainshock and the aftershocks of the Sierra Madre earthquake sequence, with focal mechanisms shown in equalarea projections of the lower focal hemisphere. Most of the events (groups I and II) are located within $5 \mathrm{~km}$ west of the mainshock. They have similar waveforms to the mainshock. The mechanisms determined for these events are thrust and are essentially similar to that of the mainshock. The events located just south of the mainshock show a combination of strike-slip and thrust faulting mechanisms. A few aftershocks located to the east of the mainshock have strike-slip mechanisms. The different mechanisms of some of the aftershocks indicate a complex structure of the fault (Hauksson and Jones, 1991). The location and mechanism of the mainshock and aftershocks suggest that the Sierra Madre earthquake sequence probably occurred on the Clamshell-Sawpit fault.

The focal mechanisms and seismic moments of the mainshock and aftershocks of the Sierra Madre earthquake thus determined are listed in Table 1. We compared the ratio of cumulative seismic moments of the aftershocks to that of the mainshock for the Sierra Madre earthquake sequence with the ratios for 13 other earthquake sequences in California. The method is similar to that of Ma and Kanamori (1991). The ratio for the Sierra Madre sequence is about $1 / 50$, which is larger than the ratio, $1 / 1000$, for the 1988 Pasadena earthquake sequence, but is smaller than that for most earthquakes in California. The average ratio of most of the events in California is about $1 / 5$.

\section{$Q$ and Stress-Drops Determination}

The quality factor, $Q$, is an important parameter of the crust, in addition to the seismic velocities, for understanding wave propagation. Also, the attenuation property provides information about the degree of fracturing in the crust. The broadband waveform observed at short distances contains information about the source dimension and the attenuation characteristics of the medium along the path. Here, we attempt to use broadband data observed at short distances to determine the attenuation property of the crust and stress drops of earthquakes. The stress drop, determined from the seismic moment and the source dimension, provides information about the state of stress in the fault zone. Although the detailed relationship between the tectonic stress field and earthquake stress drops is not known, stress drop is still a fundamental property of earthquakes and it is important to determine it for different tectonic provinces.
If there is no attenuation (i.e., if the medium is perfectly elastic); the width of the observed seismic pulse ( $P$ or $S$ waves) is in general proportional to the source dimension. However, the actual waveform and pulse width depend on the details of the rupture parameters such as fault geometry, the rise time of local dislocation function, rupture length, rupture mode (unilateral, bilateral, etc.), and the source complexity. Nevertheless, on the average one would expect a linear relationship between the pulse width and the source dimension, and many studies have been made using an average relationship between the pulse width and the source dimension. For example, Cohn et al. (1982), using a circular fault model of Brune (1970), obtained the relation

$$
\tau=2.62 a / \beta,
$$

where $\tau$ is the source time duration in seconds, $a$ is the radius in kilometers, and $\beta$ is the shear velocity in the vicinity of the source. For a circular fault, the stress drop, $\Delta \sigma$, is written as

$$
\Delta \sigma=\frac{7 M_{0}}{16 a^{3}}
$$

(Eshelby, 1957), where $M_{0}$ is the seismic moment in dyne$\mathrm{cm}$. Substituting $\tau$ in equation (3) into equation (4), we obtain

$$
\tau=\frac{5.69 \times 10^{-3}\left(M_{0}\right)^{1 / 3}}{(\Delta \sigma)^{1 / 3}}
$$

for a shear velocity of $3.5 \mathrm{~km} / \mathrm{sec}$. As is evident from its derivation, equations (3), (4), and (5) should be considered valid only in an average sense. Nevertheless, equation (5) can be used to estimate average stress drops of regional events from the pulse width.

If attenuation is included, the pulse width of the observed waveform increases as $Q$ decreases. For a given $\tau$ and $Q$, we can compute the waveform at the station by convolving a triangle source time function with the Futterman $Q$ operator (Futterman, 1962). Since the observed pulse shape is usually not a simple triangle function, we define the equivalent width $W_{e}$ by the expression

$$
W_{e}=\frac{\left[\int f(t) d t\right]^{2}}{\int[f(t)]^{2} d t}
$$

where $f(t)$ is the time history of the wavelet of which the pulse width is to be estimated. This expression is analogous to a similar expression used in Blackman and Tukey (1958) to define the effective width of a power spectrum.

Since PAS is near a node of the $P$-wave radiation 

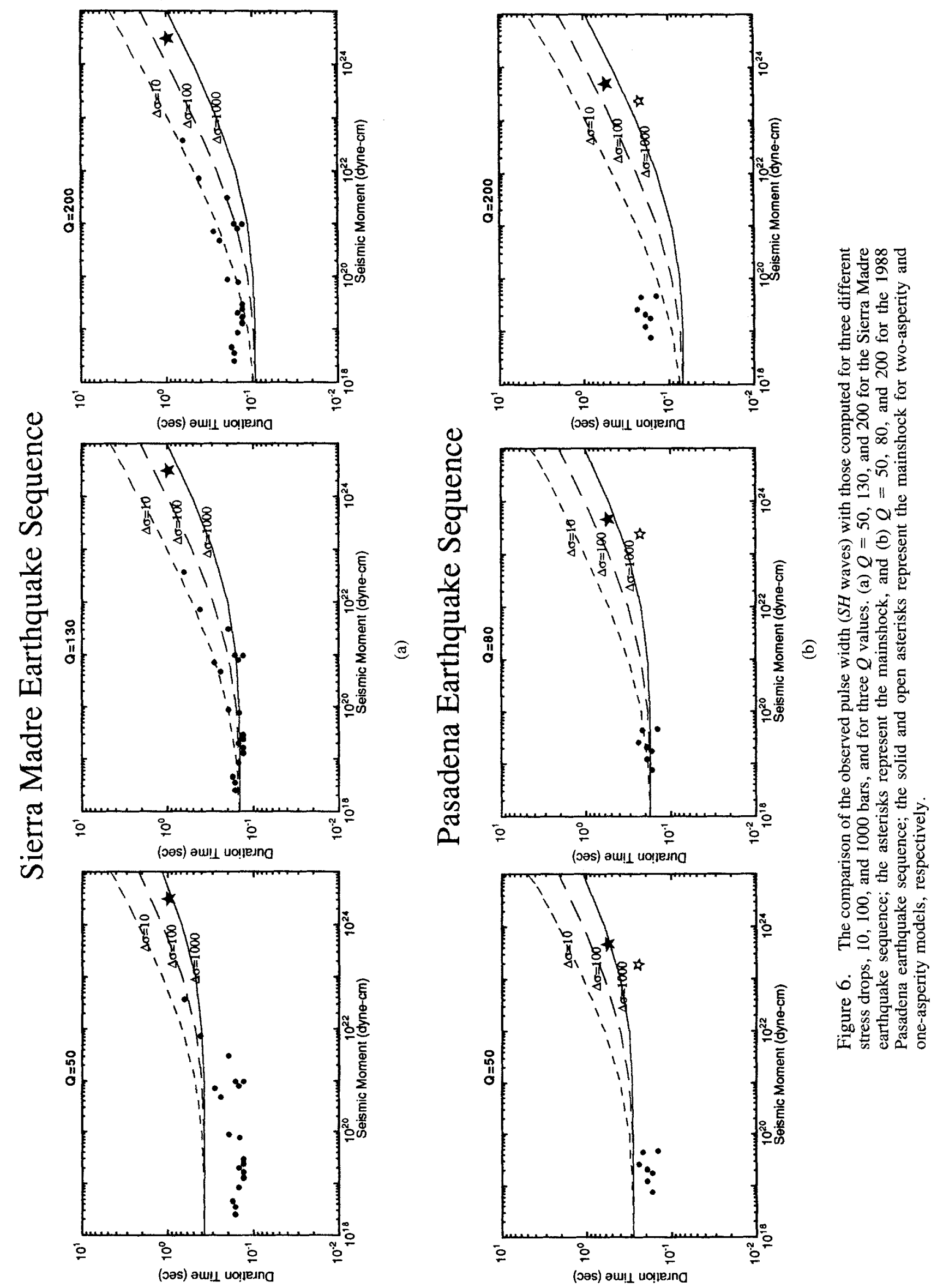
pattern of most of the events in the Sierra Madre earthquake sequence, the $P$ waves are usually small. To avoid the effect of $P-S V$ conversion at the free surface, we measured the pulse width of the $S$ wave on the transverse component. The curves in Figure 6a show the relation between $W_{e}$ and $M_{0}$ for various stress drops and $Q$. If the seismic moment is less than about $10^{20}$ dyne-cm, the pulse width is essentially determined by $Q$, and $W_{e}$ tends to a constant value regardless of $\Delta \sigma$. We compared $W_{e}$ computed for various values of $Q$ and $\Delta \sigma$ to that of the observed and determined the average $Q$ along the path from the hypocenter to PAS and $\Delta \sigma$ of the events.

For events with a seismic moment less than $10^{20}$ dyne$\mathrm{cm}$, the observed data fit the curve for $Q=130$. Since we assumed that the observed pulse width of the $S$ wave represents the narrowest pulse width at PAS after the consideration of $Q$, the $Q$ value thus obtained is considered as a lower bound of $Q_{\beta}$ along the path to the PAS station. As shown in Figure 6a, the stress drop of the mainshock is between the curves with stress drops of 100 and 1000 bars for $Q=130$. It yields an approximate stress drop of 500 bars for the mainshock. Most of the aftershocks with seismic moments larger than $10^{20}$ dyne$\mathrm{cm}$ have stress drops between 10 and 100 bars, which are much smaller than the stress drop of the mainshock and comparable to the stress drops of most earthquakes (Kanamori and Anderson, 1975).

We apply the same method to the 1988 Pasadena earthquake. This earthquake occurred only about $5 \mathrm{~km}$ away from the PAS station. Figure $6 \mathrm{~b}$ shows the comparison of the observed and computed pulse widths for various stress drops of 10,100 , and 1000 bars for different $Q$ values of 50,80, and 200. The average $Q_{\beta}$ of 80 can explain the observed data generally well for events with seismic moments less than $10^{20}$ dyne-cm. Kanamori et al. (1990) suggested that the 1988 Pasadena earthquake was a double event and consisted of two asperities. From the comparison in Figure $6 \mathrm{~b}$, we estimated stress drops of about 800 and 1500 bars for the two asperities and one asperity, using the respective pulse, widths, respectively. Since most of the aftershocks of the 1988 Pasadena earthquake have seismic moments less than $10^{20}$ dyne-cm, the stress drops of the aftershocks are difficult to determine.

The different $Q$ values obtained from the Sierra-Madre and Pasadena earthquake sequences may be caused by the structure underneath the PAS station. One possibility for the low $Q$ for the Pasadena earthquake is the fact that the path from the hypocenters of the events of the Pasadena earthquake sequence to the PAS station is within the fault zone of the Raymond fault. Dreger (1992) used $Q_{\beta}$ of 300 bars in his waveform modeling at PAS station for the two large aftershocks of the 1991 Sierra Madre earthquake. However, he suggested that the value of 300 bars might be too high.

\section{Conclusions}

We determined the focal mechanisms and seismic moments of the mainshock and 21 aftershocks of the 28 June 1991 Sierra Madre earthquake sequence by applying an inversion method to the waveform data with the first-motion data as constraints. We classified the events into different groups according to epicenters and waveforms recorded at station PAS. The similarities in waveforms of the events suggest similarities of the mechanisms and locations. Most of the aftershocks located within $5 \mathrm{~km}$ west of the mainshock are similar to the mainshock in waveform. The mechanisms determined for these events are essentially similar to the thrust fault mechanism of the mainshock. A few aftershocks located to the east of the mainshock have strike-slip mechanisms and different waveforms. The mechanisms indicate thrust motion on the Clamshell-Sawpit fault, which is consistent with the results of mechanisms found with first-motion data only (Hauksson, 1992). The variation in aftershock mechanisms, especially to the east of the mainshock, suggests complexity of the fault structure. Some mechanisms from our waveform inversion are very different from those of first-motion data. This suggests that the faulting mechanism during the beginning of rupture is different from the overall faulting.

The ratio of the cumulative aftershock seismic moment to the mainshock seismic moment of the Sierra Madre earthquake is smaller than that for most earthquakes in California. The average $Q_{\beta}$ values along the paths from the hypocenters of the Sierra Madre and Pasadena earthquake sequences to station PAS are about 130 and 80 , respectively. The difference might be caused by the structure underneath the PAS station. The path for the 1988 Pasadena earthquake sequence is in the fault zone of the Raymond fault. The stress drop of the mainshock of the Sierra Madre earthquake sequence is about 500 bars. Most of the aftershocks have stress drops between 10 and 100 bars.

\section{Acknowledgments}

We thank Egill Hauksson for the information on the locations, first motions, and first-motion mechanisms of the events. This work was partially supported by the USGS Grant Number 14-08-0001-G1774. Contribution Number 5415, Division of Geological and Planetary Sciences, California Institute of Technology, Pasadena, California.

\section{References}

Blackman, R. B. and J. W. Tukey (1958). The Measurement of Power Spectra, Dover Publication Inc., New York, $190 \mathrm{pp}$.

Brune, J. N. (1970). Tectonic stress and the spectra of seismic shear waves from earthquake, J. Geophys. Res. 75, 4997-5009.

Cohn, S. N., T. L. Hong, and D. V. Helmberger (1982). The Oroville earthquakes: a study of source characteristics and site effects, J. Geophys. Res. 87, 4585-4594.

Dreger, D. S. and D. V. Helmberger (1991). Source parameters of 
the Sierra Madre earthquake from regional and local body waves, Geophys. Res. Lett. 18, 2015-2018.

Dreger, D. (1992). Modeling earthquakes with local and regional broadband data, Ph.D. Thesis, California Institute of Technology, Pasadena, 203 pp.

Eshelby, J. D. (1957). The determination of the elastic field of an ellipsoidal inclusion and related problems, Proc. R. Soc. London, Series A, 241, 376-396.

Futterman, W. I. (1962). Dispersive body waves, J. Geophys. Res. 67, 5279-5291.

Hauksson, E. (1994). The 1991 Sierra Madre earthquake sequence in southern California: seismological and tectonic analysis, Bull. Seism. Soc. Am. 84, 1058-1074.

Hauksson, E. and L. M. Jones (1991). The $1991\left(\mathrm{M}_{\mathrm{L}}=5.8\right)$ Sierra Madre earthquake in southern California, seismological and tectonic analysis, EOS, 72.

Kanamori, H. and D. L. Anderson (1975). Theoretical basis of some empirical relations in seismology, Bull. Seism. Soc. Am. 65, 10731095.

Kanamori, H., J. Mori, and T. H. Heaton (1990). The 3 December 1988 Pasadena earthquake $(M=4.9)$ recorded with the very broadband system in Pasadena, Bull. Seism. Soc. Am. 80, 483487.

Kanamori, H., E. Hauksson, and T. H. Heaton (1991). Experiment towards realtime seismology using TERRAscope: the 1991 Sierra Madre earthquake, EOS, 67.

Ma, K.-F. and H. Kanamori (1991). Aftershock sequence of the 3 December 1988 Pasadena earthquake, Bull. Seism. Soc. Am. 81, 2310-2319.

Reasenberg, P. and D. Oppenheimer (1985). FPFIT, FPPLOT, and FPPAGE: Fortran computer programs for calculating and displaying earthquake fault-plane solutions, U.S. Geol. Surv. OpenFile Rept. 85-739..

Wald, D. J. (1991). Strong motion and broadband teleseismic analysis of the 1991 Sierra Madre, California, earthquake, J. Geophys. Res. 11033-11046.

Seismological Laboratory

California Institute of Technology

Pasadena, California 91125

Manuscript received 28 May 1993. 